\title{
Stereotactic Transplantation of Foetal Ventral Mesencephalic Cells: Cuban Experience from Five Patients with Idiopathic Parkinson's Disease
}

\author{
H. Molina, R. Quiñones, L. Alvarez, I. Ortega, J.L. Muñoz, C. González, K. de la Cuétera, \\ O. Torres, C. Suárez, M. Leōn, M.J. Rojas, M. Rachid, R. Macías, J.C. García, N. Pavōn, \\ L. Lorigados, O. Castellanos and $\mathrm{O}$. Hernăndez
}

\begin{abstract}
Centro Iberolatinoamericano de Transplante y Regeneraciфn del Sistema Nervioso, Avenida 25 \# 15805, entre 158 y 160, Playa, Ciudad de La Habana, Cuba
\end{abstract}

From April to December 1987, after having carried out rodent neurografting studies, we performed adrenal medulla autotransplantation on three patients with severe Parkinson's disease. From January 1988 to April 1990, thirty parkinsonian patients underwent foetal ventral mesencephalic tissue transplantation in the caudate nucleus, using an open microsurgical procedure.

The stereotactic neurotransplantation technique was first applied in Cuba in March 1992. Five patients with idiopathic Parkinson's disease (Hoehn \& Yahr Stage 4) were selected according to CAPIT criteria. Their mean age at time of surgery was 51 years, the evolution time of the disease ranged from 7 to 13 years; and they had been receiving L-Dopa for a mean period of 9 years. All of them had motor complications associated with chronic L-Dopa therapy, such as dyskinesias, freezing, and complex fluctuations in motor condition. The presurgical mean "off" time was $57.6 \%$ of the waking day, but in "on" conditions the patients spent $11.2 \%$ of the day with disabling dyskinesias.

Using the Leksell Stereotactic System, we performed computer-assisted CT-guided stereotactic transplantation of foetal ventral mesencephalic cell suspensions, into the right caudate and putamen. The post-conception ages of foetuses were 8-13 weeks; the mean time between abortion and implantation was 2 hours 42 minutes; and the graft cell viability ranged from 52 to $80 \%$.

The clinical assessment of the patients carried out during twelve months before surgery and three months after transplantation revealed a progressive reduction in both the daily time spent in "off" conditions from $57.6 \%$ before surgery to $12.5 \%$ three months after transplantation, and the number of daily "off" periods per day from 4.4 to 1.5 .

In the 3 rd post-operative month, the patients showed, as a general pattern, a significant improvement in their neurological performance (from 108.8 to 59.5 in I[DRS), a less severe disability during "off" periods (Fig. 1), and increase of "on" time predominantly without dyskinesias (from 31 to $89 \%$ ), according to international rating scales for Parkinson's disease.

Timed neurological tests were performed in the post-surgical periods before and after the first daily L-Dopa dose. Beginning in the 7th week after grafting there was a significant bilateral improvement of movement speed in both "off" and "on" periods, mainly contralateral to the transplantation site, and a progressive reduction of the pre-surgical differences between "off" and "on" performance time.

In the post-operative stage, we adopted the pharmacotherapeutic strategy of administering L-Dopa in slowly increasing doses, to obtain the best neurological conditions. The patients' sensitivity to L-Dopa increased after transplantation, allowing us a wider time interval between doses, and a gradual reduction of the mean dose from $1000 \mathrm{mg}$ per day before surgery to 409.5 mg daily, three months after implantation.

Dopaminergic drug responses were assessed before and after surgery. The results of the pharmacological tests proved post-operative changes in the pattern of the single dose L-Dopa response: the motor performance improved sig- 


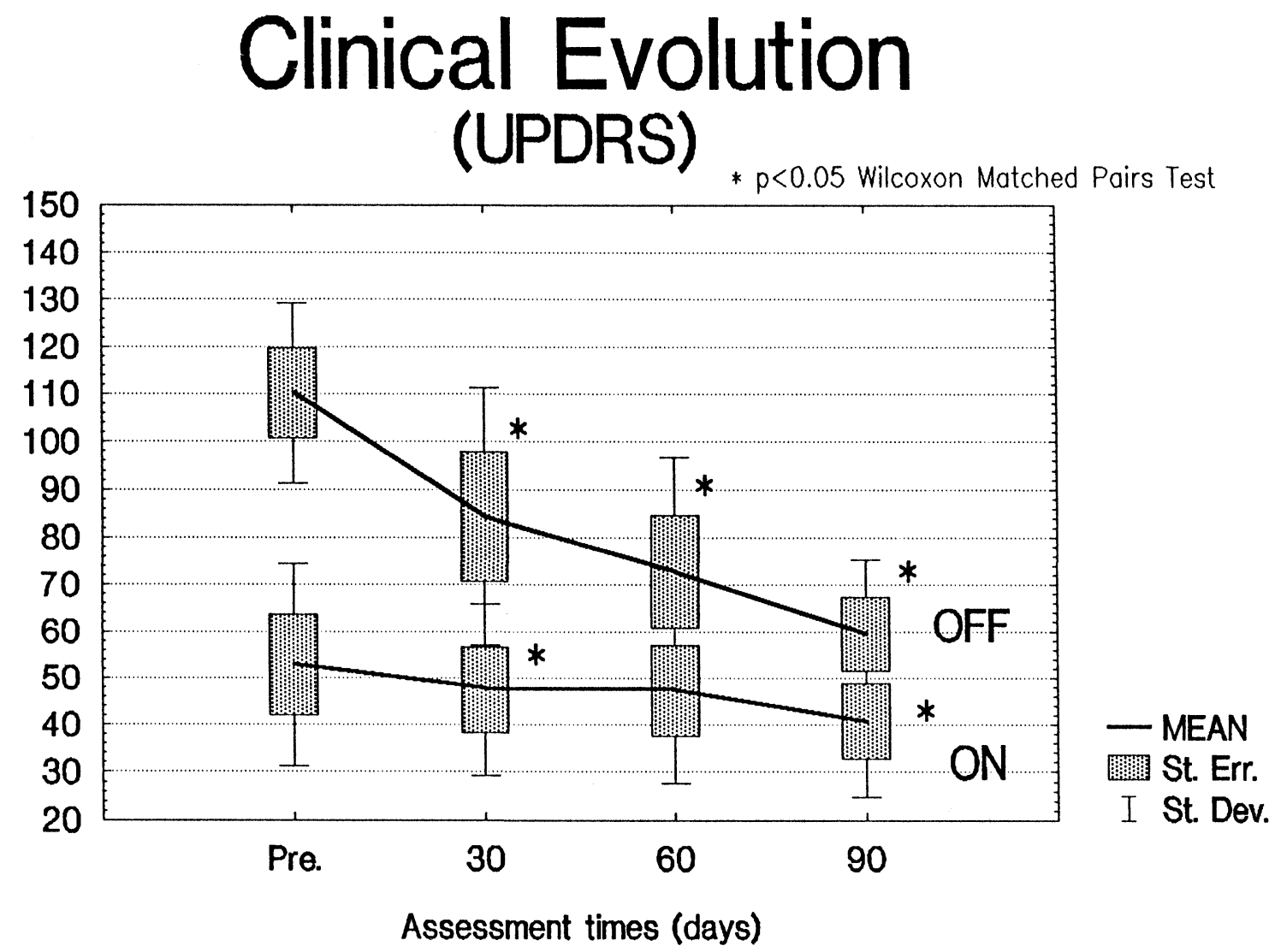

Fig. 1: Clinical evolution from 12 months before to 3 months after transplantation.

Progressive clinical improvement statistically significant from 1 to 3 months after grafting $(P \leq 0.05)$ (Wilcoxon matched pairs test).

nificantly, the "on" latency shortened from 76 minutes pre-surgery to 25 minutes three months after grafting, and the beneficial time-effect of L-Dopa increased from 84 minutes before to 265 minutes in the 3rd post-operative month.

The post-surgical improvement in our patients can be summarized as follows:

- Motor complications associated with L-Dopa therapy: reduced.

- Response to L-Dopa treatment: improved.

- Daily requirements of L-Dopa: reduced.

- Parkinsonian symptoms: reduced.

- Neurological performance: improved.

- Quality of life: improved.
Finally, based on the research conducted over more than four years in the field of neural transplantation and as a result of our most recent experiences, we conclude that transplantation of dopaminergic cells may improve the neurological condition of parkinsonian patients suffering from motor complications associated with L-Dopa therapy. 

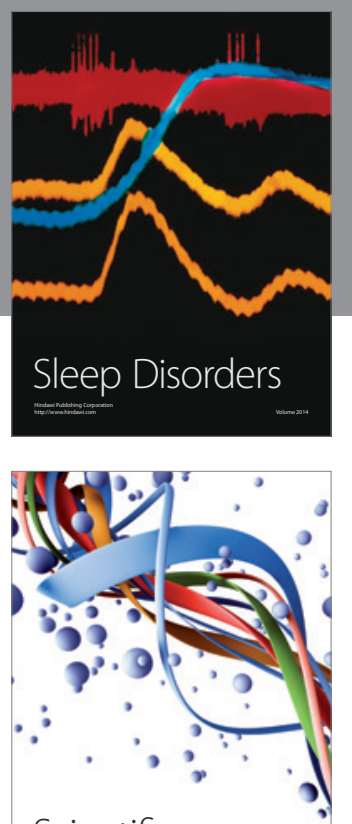

Scientifica
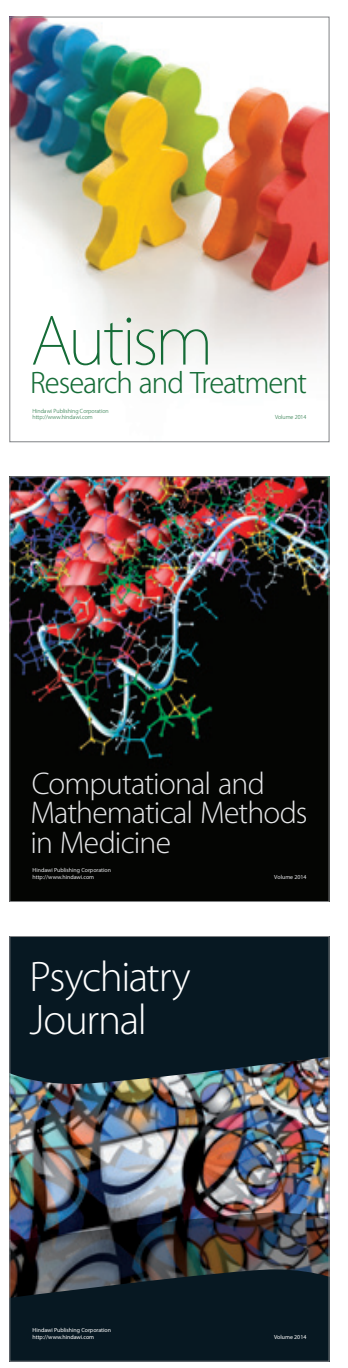
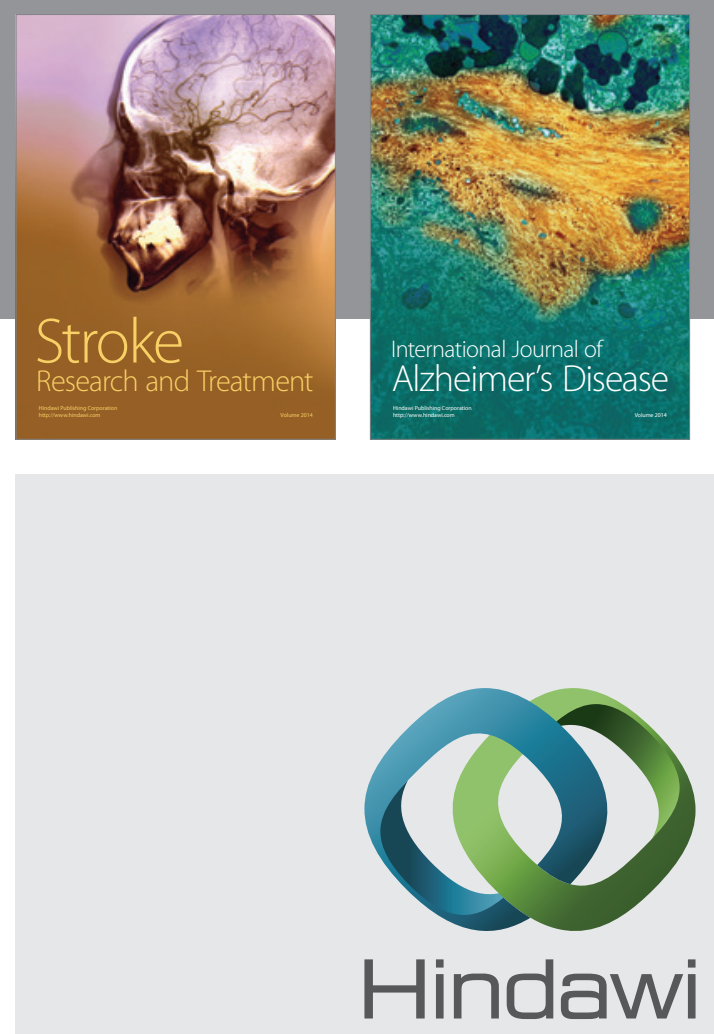

Submit your manuscripts at

http://www.hindawi.com
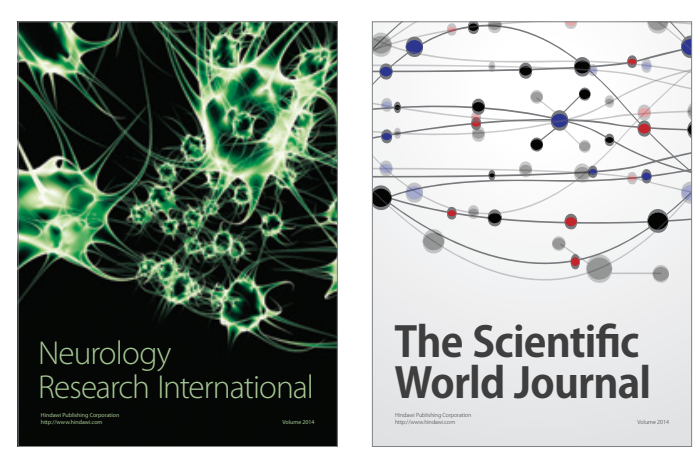

The Scientific World Journal

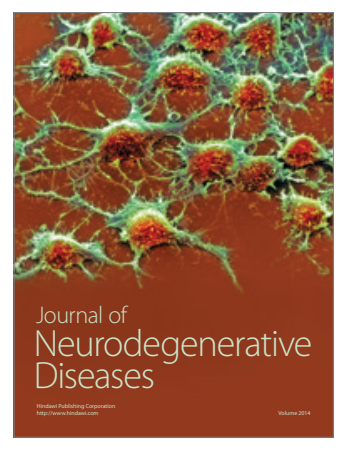

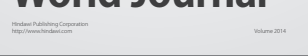

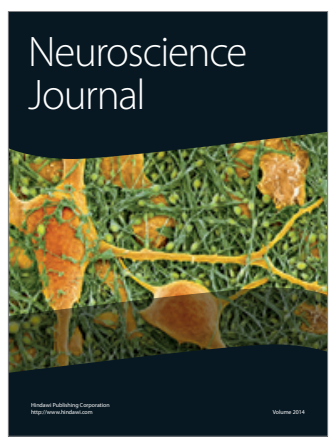

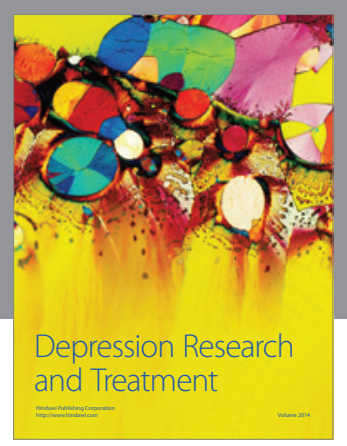
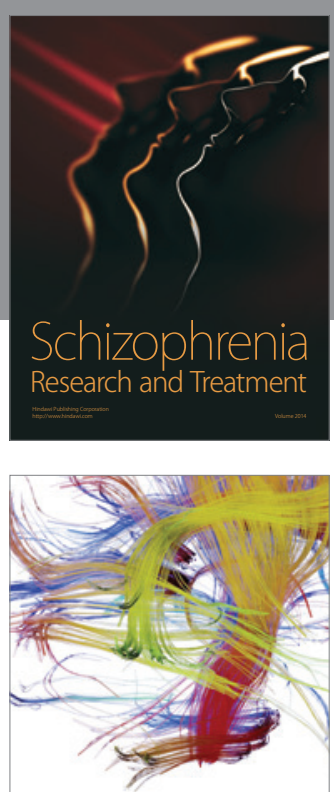

Brain Science

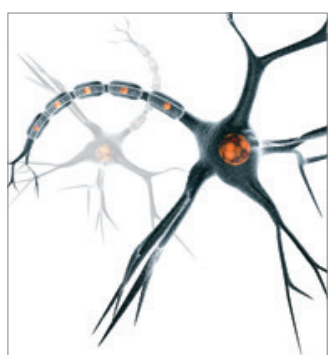

Neural Plasticity
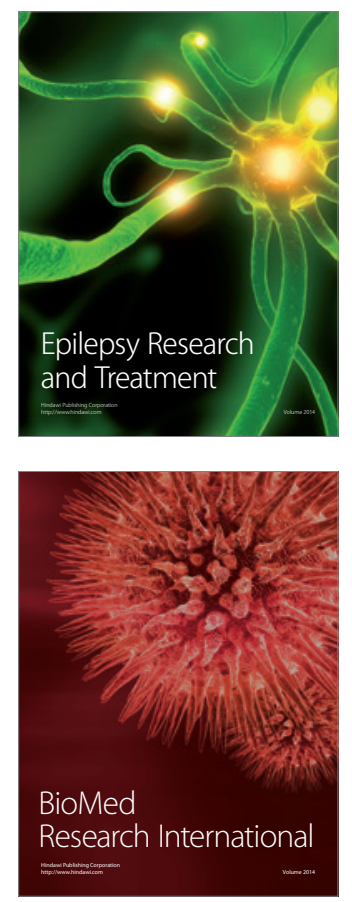

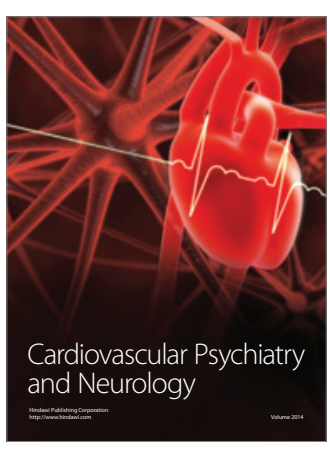

Parkinson's

Disease
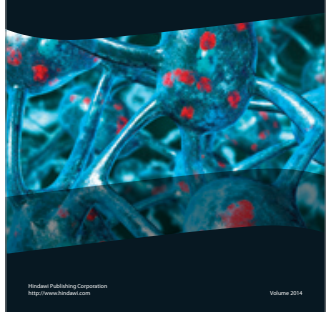